\title{
Dental Phobia Acquired in Childhood
}

\author{
Beenish Khalil BDS
}

\begin{abstract}
:
A hospital based study was conducted to investigate the major causes of establishment of phobia established in the childhood

OBJECTIVE: The objective of this study was to investigate the dental phobia in adults acquired during childhood

METHODOLOGY: A questionnaire was completed and data was collected from 60 patients (age 16-40) who were afraid to have dental treatment due to some negative and traumatic experience during early childhood. The data was analyzed using SPSS 19.0 and Microsoft excel.

RESULTS: A total of 60 patients aged 16-40 were evaluated, of which 32 were male and 28 were female. The average anxiety level for male and female was the same and there was no significant gender difference. Majority (58\%) developed phobia when they were treated at 5-6 years of age. Majority of respondents developed phobia at government hospital (53\%). Endodontic treatment (43\%) and exodontia (38\%) were the most fear provoking procedures.
\end{abstract}

CONCLUSION:. Treatment at young age, treatment at government hospital and endodontic treatment were most frequent reasons for childhood phobia among study participants.

KEYWORDS: Dental Phobia, Dental treatment, Pediatric dentistry, behavior management.

HOW TO CITE: Khalil B. Dental Phobia Aquired in Childhood. J Pak Dent Assoc 2017; 26(1): 6-9

Received: 22 December 2016, Accepted: 24 March 2017

\section{INTRODUCTION}

A behavior that leads to complete avoidance of a particular situation due to continuous fear of that situation is called as phobia. Fear is manifested in the form of anxiety which is provoked when the person is exposed to a particular stressful situation or stimulus. Over a period of time the anxiety converts into the panic attacks resulting in the establishment of restlessness and distress and disturbing the routine life of that person. A phobic will spend a lot of time thinking about fearful situations. Dental phobia is mainly identical to fear, only difference is its much stronger. The panic attacks can be provoked even by reminding the particular situation resulting in the avoidance of treatment. This painful response is mainly the reaction of some traumatic experience in the past either due to mishandling by dentist or dental auxillary. These incidents have a strong impact on the memory if they are caused in early childhood.

Islamic International Dental College Pakistan

Corresponding author: < beenishkhalil@ hotmail.com >
What ever be the type of fear and reason of the fear the dentist is considered as a culprit behind all these faults resulting in the development of fear and phobia. ${ }^{1}$ Exogenous and endogenous anxieties are another types of fear classified in some other systems ${ }^{2}$. University of Washington Categorized Dental Fear into four main categories i-e fear of specific stimuli and distrust of Dentist which are usually the result of past bad experience are categorized as exogenous while the generalized anxiety and fear of a medical emergency can be groups as endogenous ${ }^{3}$ most of the dental phobias are caused due to bad handling of the doctor ${ }^{4}$. This includes some painful procedure performed in dental clinic as well as some sort of psychological setback such as being humiliated or disgraced by a doctor or auxiliary. Careless dental professional is considered to be another big reason. The major psychological impact is not the pain itself rather the cold behavior of the dentist is the main disturbing thing resulting in establishment of fear of loss of control ${ }^{2}$. Another reason of dental anxiety or phobia is established through listening to the stories of other people if a parent is scared and anxious about dental treatments or dental settings including the dentist, children even in the absence of any directly faced bad or painful experience will learn to be 
afraid as well ${ }^{5}$. Post-Traumatic Stress is another big contributing factor. Post traumatic stress disorder is strongly related to past experience that is horrific. it has been revealed that previous negative treatment and experiences have strong influence on the child psychology resulting in the averting behavior and fear towards the treatment it is directly linked to the genesis of fear in children ${ }^{6}$. On the other hand, fear can also be acquired through the negative modelling by the siblings and parents as a matter of fact ${ }^{7}$.

Although the national literature is replete with reports about frequency and various associated with dental anxiety, there are very few that focus a bad experience in childhood as a reason for adult dental phobia. It was therefore, the objective of the present study to investigate the specific causes of dental phobia acquired during childhood but manifested in adult age.

\section{METHODOLOGY}

A cross sectional study was conducted in Islamic International Dental Hospital and 2 established private clinics of Islamabad. The consent from the patients were obtained after proper explanation of the study from individuals who were willing to participate. Patients suffering from dental phobia belonging to either gender and age between 16-40 were included. A open ended format questionnaire was designed and self distributed to the patients. The questionnaire was composed of 12 questions. Data was collected from 60 patients using convenience sampling based upon the number of the patients available in the available period of time.. The data was analyzed using SPSS version 19.0 software for MS Windows.

\section{RESULT}

A total of 60 patients aged 16-40 were evaluated, of which 32 were male and 28 were female. The average anxiety level for male and female was the same and there was no significant gender difference. $16 \%$ of the total patients were at the age of 7-8 years when they have undergone through the treatment that resulted in the development of fear and phobia. $58 \%$ were in the age group of 5-6 years while $25 \%$ were 4 years of age.

Majority of respondents developed phobia at government hospital (53\%) followed by private hospital (31\%) and private clinics $(15 \%)$. (Fig no. 1) Investigating the behavior of Dental practitioner, $85 \%$ of the patients were of the view that they were not able to follow the dentist's instructions and were not briefed about the nature of treatment prior to its commencement. Similarly, $45 \%$ reported that the dentist behaved rudely, and in an un-cooperative (26\%) manner (fig no 2). Majority (78\%) were not satisfied with environment of the dental setting.

Dental anxiety appeared to vary by type of treatment, with restorative / endodontic and exodontic patients reporting higher levels of anxiety, $43 \%$ and $38 \%$ respectively followed by patients receiving periodontal $(11 \%)$ and prophylactic treatment (6\%) (fig. no 3). Whereas, $88 \%$ patients reported to experience pain intra-operatively while $63 \%$ reported post-operative pain as well.

According to study participants' self-assessment of the anxiety levels, $11 \%$ considered themselves as cooperate while $30 \%$ were of the view that they were highly irritable and the rest 58\% regarded themselves as intensely anxious.

Psychological responses to dental phobia appeared as an amalgamation of worry regarding the white coat of the doctor $(11 \%)$, about $16 \%$ were upset with the sound of the drill, the fear of pain and discomfort that might be caused during the treatment was the cause of panic in 33\% of the patients while the feeling of helplessness and insecurity accounted for $18 \%$. The atmosphere of the clinic was the source of disturbance for almost $20 \%$ of the patients.

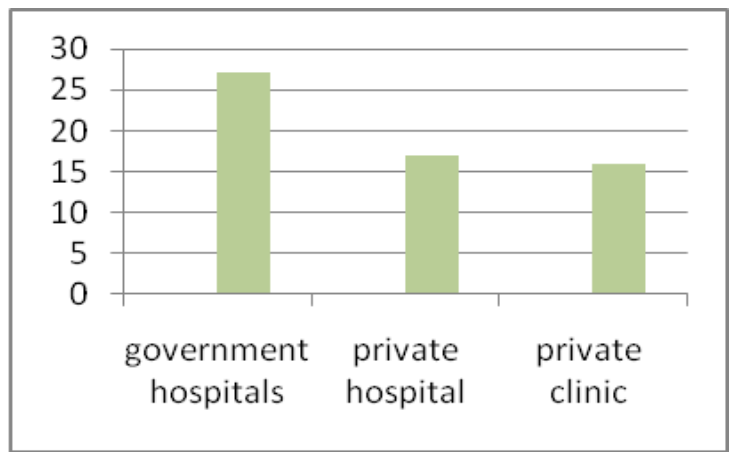

Fig. (1).

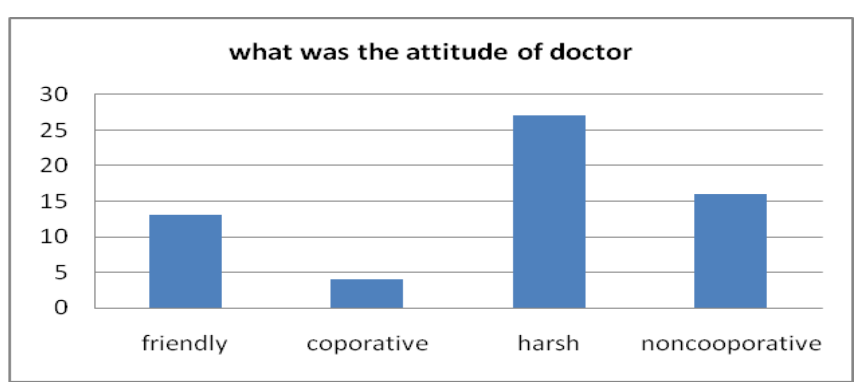

Fig. (2). 


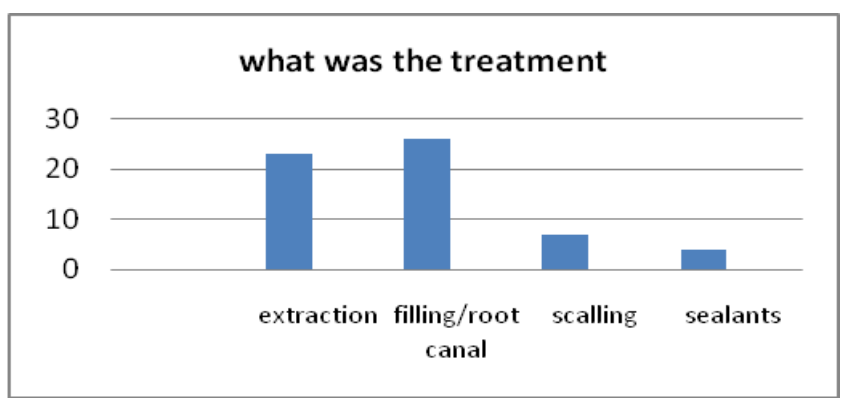

Fig. (3).

\section{DISCUSSION}

A perturb emotion strongly provoked by danger or pain is known as fear, irrespective of the fact that it is real or fabricated a fear that is incontrollable and irrational turns into a phobia. It is creditable to note that most of the time fears are boosted by irrational imagination ${ }^{8}$ fear conditioning is referred to the type of the fear that is acquired through specific learning. Either through personal experience of a traumatic or painful event ${ }^{9}$. The root cause of phobia and anxiety, specifically in the dental setting, has a intricate and multi-factorial physiological and psychological etiology ${ }^{10}$. Several factors contribute to the etiology of dental phobia an innate predisposition, conditioning differences in psychological behavior and fear associated with the direct stimulation or non-associative perspective are considered to be the four universal causes ${ }^{9}$. The most important and common cause of dental phobia is the negative traumatic and painful event in the childhood mostly early childhood ${ }^{10}$. An offensive, discourteous and ungracious behavior of the dental professional act as the initial stimulus which precipitate the patterns of fear and anxiety ${ }^{11}$. The anxiety of the caretaker specially the mother directly influences the child $^{12}$. The children look towards their parents and consider them role as a model for themselves ${ }^{13}$. Along with the behavior the physical appearance, facial expression, tone and pitch of voice are also considered as triggers for dental fear. So both verbal and nonverbal factors are important for consideration in order to avoid the establishment of phobia in the early childhood ${ }^{14}$. Mean while the alterations in the dental care delivery system and the behavior of the dental professional may not be ample to deal with the phobias and fears if the behavior of the parents and the children are not checked they need to be focused at the first pace ${ }^{15}$. Another big causative impact factor is the environment of the clinic or the setting ${ }^{16}$. Fortunately, most of the professionals are competent in managing fearful and phobic patients and have developed number of ways that helps in reducing the pain and assuage fear in the dental setting ${ }^{17}$. Relaxation strategies are proved to be very successful in relieving the anxiety resulting in the slowing down of the physical reactions of the body in response to anxiety and fear. Deep breathing exercises like simple breathing followed by paced inhalation and exhalation proved to be very useful. likely Progressive muscle relaxation which involves sequentially tensing and relaxation of particular group of muscle may also be helpful ${ }^{18}$. If time constraint is not a problem than using relaxational strategies along slow and gradual exposure to the object one is afraid of is known as systemic desensitization and is considered as very effective method ${ }^{19}$. The tell show and do technique in which the child is slowly been exposed to the thing or aspect he is worried of until he become able to overcome that fear as an example if a child is afraid of the injections the dentist must start by slowly explaining the parts of injections until he become able to touch that syringe and completely understands its purpose with little to no anxiety ${ }^{18}$. Distraction techniques are also considered to be supportive and aiding. This type of strategy usually involve using a toy in the dental chair, asking the child to remember a recent happy experience, allocating the

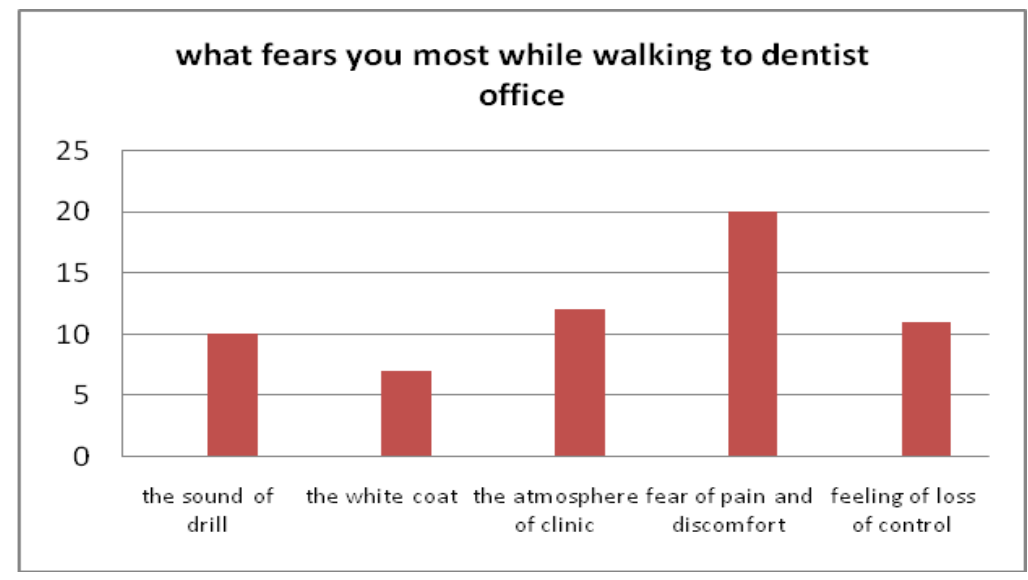

Fig. (4). 
child some task like counting the tiles in the ceiling while sitting in the office of the dentist during the treatment it will help in the deflection of the attention ${ }^{20}$. The best distraction technique is the music according to recent studies ${ }^{21}$. Awarding little compliments in response to positive behavior is very effective method ${ }^{22}$.

\section{CONCLUSION}

Within the limitations of this study treatment at young age, treatment at government hospital and endodontic treatment were most frequent reasons for childhood phobia among study participants.

\section{QUESTIONNAIRE}

\begin{tabular}{|l|l|}
\hline 1 & $\begin{array}{l}\text { What was your age when you first visited the } \\
\text { dentist office? }\end{array}$ \\
\hline 2. & Where the treatment was done? \\
\hline 3. & $\begin{array}{l}\text { Do you have any idea prior to the treatment/were } \\
\text { you mentally prepared for the treatment? }\end{array}$ \\
\hline 4. & $\begin{array}{l}\text { Were you satisfied with the atmosphere and } \\
\text { environment of the clinic? }\end{array}$ \\
\hline 5. & The attitude of the doctor and the staff was? \\
\hline 6. & What was the treatment? \\
\hline 7. & Was the treatment painful? \\
\hline 8. & Was there any post operative pain? \\
\hline 9. & You rate your attitude at the time of treatment as? \\
\hline 10. & Were your parents present at chair side? \\
\hline 11. & what was the attitude of your parents? \\
\hline 12. & $\begin{array}{l}\text { What fears you most while walking to a dentist } \\
\text { office? }\end{array}$ \\
\hline
\end{tabular}

\section{REFERENCES}

1. Bracha. HI releases a new version of ANSI/HI standards. World Pumps 2006; 2006: 5.

2. Weiner AA, Sheehan DV, Jones KJ. Dental anxiety the development of a measurement model. Acta Psychiatr Scand 1986; 73: 559-65.

3. Moore R, Brødsgaard I, Birn H. Manifestations, acquisition and diagnostic categories of dental fear in a self-referred population. Behav Res Ther 1991; 29: 5160.

4. Mineka S. Frequently fanciful facts about phobias. Psycritiques $1985 ; 30$.
5. Townend E, Dimigen G, Fung D. A clinical study of child dental anxiety. Behav Res Ther 2000; 38: 31-46.

6. Milgrom P. Origins of childhood dental fear. Behav Res Ther 1995; 33: 313-9.

7. Armfield J, Spencer A, Stewart J. Dental fear in Australia: Who's afraid of the dentist? Aus Dent J 2006; 51: 78-85.

8. Armfield JM. Cognitive vulnerability: A model of the etiology of fear. Clin Psychol Rev 2006; 26: 746-68.

9. Eli I. h Oral Psychophysiology; Stress, Pain, and Behavior in Dental Care. 1992. CRC Press Inc. Boca Raton, Florida p. 61-62.

10. Kent GG, Blinkhorn AS. The Psychology of Dental Care. p.66)

11. Rachman S. The Conditioning Theory of Fear Acquisition: A Critical Examination. Behav Res Ther. 1977, 15; 375-87

12. Johnson R, Baldwin DC. Relationship of Maternal Anxiety to the Behavior of Young Children Undergoing Dental Extraction. J Dent Res. 1968; 47; .801-5.

13. Milgrom $\mathrm{P}$, Vignehsa $\mathrm{H}$, Weinstein $\mathrm{P}$. Adolescent Dental Fear and Control: Prevalence and Theoretical Implications. 1992. Behav Res Ther; 30; 367-73.

14. Halberstadt AG. Family Socialization of Emotional Expression and Nonverbal Communication Styles and Skills. J Pers Soc Psychol. 1986, 51 ; 827-36.

15. Denham SA, Zoller D, Couchoud EA. Socialization of Preschoolers Emotion Understanding. 1994. Dev Psychol. 30; ; 928-36

16. Shi L, Stevens GD. Vulnerability and Unmet Health Care Needs. 2004. J gen intern Med, 20: 153.

17. Callear A, Harvey ST, Bimler D. Understanding the structure of children's emotion-regulation strategies. Int J Behav Dev 2016;

18. Armfield J, Heaton L. Management of fear and anxiety in the dental clinic: A review. Aus Dent J 2013; 58: 390-7.

19. Razani J. Treatment of phobias by systematic Desensitization. Arch Genl Psyc 1974; 30: 291.

20. Martin V. Using distraction techniques with children. Nursing 2013; 43: 68.

21. yamini $\mathrm{V}$ V. Effectiveness of music distraction in the management of anxious pediatric dental patients. Annals Ess Dent 2010; 2: 1-5.

22. ten Berge $M$. Dental fear in children: Clinical consequences suggested behaviour management strategies in treating children with dental fear. European Arch Paediat Dent 2008; 9: 41-6. 